\title{
Managing Greenhouse Gas Emissions for Airport Inventories: An Overview
}

\author{
Orazio Giuffre' \\ Department of Civil, Environmental and Aerospace engineering, Università degli Studi di Palermo \\ Viale delle Scienze, Ed. 8, 90128 Palermo, Italy \\ Tel: 39-091-23899718_E-mail: ogiuffre@unipa.it
}

Anna Granà (Corresponding author)

Department of Civil, Environmental and Aerospace engineering, Università degli Studi di Palermo

Viale delle Scienze, Ed. 8, 90128 Palermo, Italy

Tel: 39-091-23899718 E-mail: anna.grana@unipa.it

Received: August 13, 2011

Accepted: September 7, 2011

doi:10.5539/jsd.v4n5p67

\begin{abstract}
For some years now, problems relating to gas emissions that affect climate and result from human activities have assumed a global dimension of large importance. The climate is, indeed, influenced by the concentrations of some pollutants in the atmosphere; these pollutants trap the long wave radiation emitted by the Earth and alter the energy balance, causing an accentuation of the natural greenhouse effect. In this view an inventory of greenhouse gases can become the benchmark against which to measure the achievement of quantitative targets set at the political level in the fight against climate change. Contrary to a general inventory of emissions related with air quality objectives and local effects of pollutants, a greenhouse gas inventory does not set objectives purely local, but it directs efforts towards the quantification of the liability of an area compared to a global problem as climate change, also in view of possible improvements. The inventory is thus the reference for the evaluation of pre-and post-operam actions aimed at reducing the greenhouse effect, as well as for their monitoring over time. The article in an overview of the main issues of air pollution associated to airport operations and a review of the airport sources and components contributing to greenhouse gas emissions. After a brief description of the most recent international and national standards and recommendations on this topic, the article focuses on reasons for developing a greenhouse gas emission inventories and traces the essential elements in the methodology to be followed by airport operators for preparing an airport-specific inventory of greenhouse gas emissions. Methods for calculating emissions are also summarized and reviewed. Finally, the new references to the environmental sustainability at airports, as well as the main measures to be taken to reduce emissions are also identified and commented on.
\end{abstract}

Keywords: Greenhouse gas emissions, Airport emissions, Emission inventory

\section{The background}

Air pollution due to continuous and increasing combustion of fossil fuels for energy, to tropical deforestation, to industrialized agriculture and to animal husbandry extension, has gradually led to an increase in greenhouse gases (GHGs) in the atmosphere, thus raising the natural greenhouse effect of an anthropogenic component. GHGs, naturally occurring and man-made, include, but are not limited to, water vapor, carbon dioxide $\left(\mathrm{CO}_{2}\right)$, methane $\left(\mathrm{CH}_{4}\right)$, nitrous oxide $\left(\mathrm{N}_{2} \mathrm{O}\right)$, ozone $\left(\mathrm{O}_{3}\right)$ and halocarbon compounds containing fluorine (PFCs), chlorine (CFCs, HCFCs) and bromine (halons or sulfur $\mathrm{SF}_{6}$ ) (Forster et al., 2007). GHGs in the atmosphere contribute to the greenhouse effect directly when they absorb radiation; on the contrary, indirect effects occur both when greenhouse gases are produced by chemical transformations, and when the atmospheric lifetimes of a gas is influenced by another gas, as well as when a gas affects cloud formations and, more in general, atmospheric processes that alter the radiative balance of the earth. In particular, some gases, such as carbon monoxide (CO), oxides of nitrogen (NOx), sulphur dioxide $\left(\mathrm{SO}_{2}\right)$ and non-methane volatile organic compounds (NMVOCs), indirectly affect land and/or solar radiation absorption, because they share in the formation of substances in the atmosphere with a climate change impact (e.g. other greenhouse gases); for this reason, they are usually referred to as precursors (Kim et al., 2009a). Each greenhouse gas captures a different quantity of heat, because it absorbs 
and re-radiates different wavelengths of infrared light, and remains in the atmosphere at different lengths levels and lengths of time (Kim et al., 2009a). Progressive increases in concentration of the radiatively active greenhouse gases in the atmosphere cause a change in the balance between incoming solar radiation and outgoing infrared (i.e., thermal) radiation; e.g. the radiative forcing, that is a primary component of recent climate change (Kim et al., 2009b). The interference of GHGs to the dissipation of the infrared radiation emitted from the Earth results, indeed, in the accumulation of thermal energy and creates a warming influence, or in other words the increase in the average temperature of Earth's near-surface air (Oh, 2008). GHGs differ in their warming influence (radiative forcing) on the global climate system due to their different radiative properties and lifetimes in the atmosphere. It follows that radiative forcing measures the influence of a factor in altering the balance of incoming and outgoing energy in the Earth-atmosphere system; moreover, it is an index to quantify the importance of the factor as a potential climate change mechanism (Pachauri and Reisinger, 2007).

In forecasting on the effects of global warming it refers generally to the carbon dioxide; basing on the values of warming potentials of all other greenhouse gases that are compared to it, these gases can be also included. In order to compare the ability of each greenhouse gas to trap heat in the atmosphere relative to another gas without directly calculating the changes in atmospheric concentrations, the Global Warming Potential (GWP) concept has been developed. The global warming potential is the most commonly used equivalency method. GWP is expressed as the ratio of the radiative forcing resulted from $1 \mathrm{~kg}$ of a given GHG and the radiative forcing caused by carbon dioxide in the same amount over a period of time of 100 years (Forster et al., 2007). The GWP are provided by the Intergovernmental Panel on Climate Change from 2001 and are used as conversion factors to calculate emissions of all greenhouse gas emissions in $\mathrm{CO}_{2}$ equivalent. This particular topic will be reflected in the next section 5 that focuses on methods of calculating emissions. The next section frames, instead, the question in the airport context and illustrates the objectives of the research reported in this article.

\section{The airport context}

Within the sources and activities across the global economy that produce greenhouse gas emissions, the transportation sector is the third largest emitter of GHGs (the first is electricity generation and the second is industry), accounting for about 13 per cent of GHG emissions at a global level and, in particular, about 20 per cent of carbon dioxide emissions (Herzog, 2009). Aviation is one mode of transportation that, in turn, is one of many GHG emitting sectors, generating at a global level, over 730 million tons of carbon dioxide per year with an increase of 45 per cent compared to 1990 (Lepore, 2009). It is expected that growth in global air transport will triple aviation carbon dioxide emissions between 1990 and 2050, and that total radiative forcing (global warming) effects will increase fourfold over the same period (Berry et al., 2008). Moreover, air transport is the only source that emits directly into the higher levels of the atmosphere causing greater damage to the climate. ICAO Committee on Aviation Environmental Protection, during the 7th Meeting that took place in Montreal in February 2007, established that the effects of climate change emissions from aircraft of some climate-altering substances, such as carbon dioxide, are clearly identifiable and quantifiable, while the effects of other substances, such as methane or nitrogen oxides, are not yet fully quantified, making the monitoring of the aviation impact on climate more complex. Forster et al. (2008) indicated that the combined effect of emissions caused by aviation is about 3 times larger than the $\mathrm{CO}_{2}$ alone; this multiplier effect is mainly due to "radiative forcing" of the oxides of nitrogen. According to Sausen et al. (2005), aviation impact on climate change would be even up to 5 times higher than the effect generated by the emission of $\mathrm{CO}_{2}$. In Europe, $\mathrm{CO}_{2}$ emissions from aviation increased by 90 per cent from 1990 to 2005. If the current trend will continue, the growth in emissions from air transport could compromise the achievement of the reductions required to the European Union by the Kyoto Protocol. Moreover, the presence of a very busy airport activity has a very detrimental effect on global climate and on the environment: in Italy, among the major European countries for infrastructural facilities, aviation is responsible for 12 million tons of $\mathrm{CO}_{2}$ (8 per cent of total emissions from transport) and 68,000 tons of NOx, equivalent to 9 per cent of the total emitted by the transport sector (Lepore, A., 2009). It is important to consider that most of the pollutant gases (in particular, NOx) are given off during take-off and landing. Considering the Italian data, for example, almost 80 per cent NOx emitted by air transport (9.5 thousand tons in 2005) is released on take-off and landing, and then in the proximity of airports.

Airports are also sources of emissions that affect climate: emissions generated from activities occurring inside and outside the airport perimeter fence associated with the operation and use of an airport, therefore, may represent a significant danger to the health of people living near airports. Airport operators are realizing just how construction, operation, maintenance, and other activities at airport facilities can contribute to the industry's overall impacts on climate change (Berry et al., 2008). In this view a GHGs inventory can become the benchmark against which to measure the achievement of quantitative targets set at the political level in the fight 
against climate change (Van Begin. \& Van Staden, 2010).

To foster a real reduction in GHG emissions, given their impact on climate change, a process of legislative adjustments that affects the entire productive sector was triggered at a global level. An overview of the most recent international and national standard and recommendations specifically developed to govern greenhouse gases emissions is sketched out in the next section. Then, starting on reasons for developing a greenhouse gas emission inventory, this article traces the essential elements in the methodology to be followed for preparing an airport-specific inventory of GHGs emissions. Methods for calculating emissions are also summarized and reviewed. Finally, the main measures to be taken to reduce emissions and to improve the environmental sustainability at airports are also identified and commented on.

\section{The policy framework on climate change and the regulatory context on GHGs emissions}

Several factors play an important role in identifying and prioritizing the best climate change adaptation actions for airports. A regulatory regime should define what is required; voluntary programmes can fall within a framework, which provides a set of requirements, but a more comprehensive approach may need to be to achieve a well-defined purpose. The use of emission inventories to support the planning and management of air quality is, moreover, widely recognized by international law. An overview of potential climate change impacts and related adaptation strategies in relation to airports were listed by Stewart et al. (2011). In the following only a synthetic description of the main initiatives on the theme are reported.

Recognizing the problem of potential global climate change, the World Meteorological Organization and the United Nations Environment Programme established the Intergovernmental Panel on Climate Change in 1988; it is an intergovernmental body providing to policy makers a scientific evaluation of literature available on the risk of human induced climate change and on the impacts of climate change on natural and human systems, on the options for adaptation and vulnerability and on the climate change mitigation (or reductions emissions of greenhouse gases). The IPCC does not establish regulations, but develops methodological guidelines for national GHG inventories, special reports, and technical papers. The assessment reports, periodically released by the IPCC, are the basis of global agreements such as the United Nations Framework Convention on Climate Change and the Kyoto Protocol.

The United Nations Framework Convention on Climate Change is an international treaty produced by the United Nations Conference on Environment and Development held in Rio de Janeiro in 1992. The Treaty aims to achieve stabilization of GHG concentrations in the atmosphere at a level low enough to prevent dangerous anthropogenic interference with the climate system. The Treaty did not put mandatory limits for GHG emissions to individual nations and it was not legally binding; it included provisions for updates (or protocols) that would set mandatory limits on emissions. Chief among these was the Kyoto Protocol, an amendment to the international treaty on climate change, assigning mandatory targets for the reduction of GHG emissions to signatory nations. Only developed countries accepted GHG emission reduction obligations. Countries that ratified the Kyoto Protocol committed to reduce their emissions of $\mathrm{CO}_{2}$ and five other greenhouse gases $\left(\mathrm{CH}_{4}\right.$, $\mathrm{N}_{2} \mathrm{O}, \mathrm{HFC}, \mathrm{PFC}, \mathrm{SF}_{6}$ ), or engaged in emissions trading if they had maintained or increased emissions of these gases. The Kyoto Protocol provides to the Parties means to achieve emissions targets in a cost-effective way through market-based mechanisms such as: emissions trading, clean development mechanism and joint implementation. Under the Kyoto Protocol, countries' emissions have to be monitored submitting annual emission inventories or national reports at regular intervals. Emissions from international aviation were excluded from the national GHG emissions inventories and targets. International aviation emissions include all phases of flight and APU fuel burn. Inventory can be based on fuel dispensed to aircraft operating internationally, because airport operators cannot easily determine APU emissions. Emissions due to all the other activities at airports were not exempted from the Kyoto Protocol and then included in national inventories. The International Civil Aviation Organization encouraged countries to control international aviation-related emissions. Most States defined, indeed, a threshold level of emissions below which organizations are not required to report for the national inventory. The non-aircraft source emissions at airports are often below these thresholds.

The US Environmental Protection Agency also established that facilities emitting $25 \mathrm{kt}$ or more of $\mathrm{CO}_{2}$ equivalent GHG emissions per year have to respect reporting requirements submitting mandatory annual reports starting in 2011. This reporting threshold applies only to direct GHG emissions, such as fuel use in stationary sources owned (or operated) by the airport; at airports emissions from purchased electricity, or from mobile sources, such as vehicle fleets or aircrafts, are not covered by the proposed rule.

The European Union, to honor its commitments under the UNFCCC and the Kyoto Protocol, has gradually established a mechanism for monitoring and reporting of GHG emissions to make more accurate evaluations, 
and to adjust the progress achieved in reducing emissions. The main EU legislative measures (gradually accepted by member states), aimed at promoting a real reduction of GHG emissions, are listed below:

- The Directive 2003/87/EC established the European Emissions Trading Scheme providing for companies in certain sectors the limitation of GHG emissions under an established cap. The goal of the Directive was to promote reductions emissions of greenhouse gases in a cost-effective and economically efficient manner. On October 2008 the European Council adopted the Directive 2008/101/EC which reviews the Directive 2003/87/EC including aviation activities into EU ETS. Initially (2005-2007 period), the Directive applied only to $\mathrm{CO}_{2}$ emissions; currently (2008-2012 period) it takes into account all six GHGs. An interesting analysis of the implications of emissions trading scheme to aviation is delivered in Scaturro, F. and Siciliano, G. (2009).

- The Directive 2003/87/EC, as amended by the Directive 2008/101/EC, established the criteria for monitoring and reporting emissions from aviation activities, as well as criteria for the verification of emissions from the same activities.

- According to the Directive 2003/87/EC, the Decision 2007/589/EC established guidelines for monitoring and reporting of GHGs emissions. The Decision 2007/589/EC, amending the 2009/339/CE, established to include guidelines for monitoring and reporting of GHG emissions and tons-km data for air transport activities.

- The Directive 2009/29/EC amended the Directive 2003/87/EC, introduced more stringent emission limits and stipulated that EU-wide quantities of emissions (to be issued in the period 2013-2020) were adjusted to take account of emissions from installations carrying out additional activities included in the scope of the Directive. The targets to be achieved by 2020 are: i) $20 \%$ reduction in emissions of greenhouse gases, ii) a $20 \%$ saving energy, iii) increasing to $20 \%$ the consumption of renewable sources.

International Standards Organization (ISO) publishes the Guidance material on an Environmental Management System (EMS). The main ISO regulation references aimed at promoting an EMS to address a real reduction of GHG emissions are listed briefly below:

- ISO 14001:2004 Environmental management systems - Requirements with guidance for use is applicable to any organization that wants to implement and to maintain an EMS and to assure conformity of the own environmental policy. It specifies requirements for an EMS and significant environmental aspects that the organization can control and/or can influence. Factors by which will depend the extent of application of this regulation are: the environmental policy of the organization, the nature of activities, products and services, the location where and the conditions in which it functions.

- ISO 14064-1:2006 Greenhouse gases - Part 1: Specification with guidance at the organization level for quantification and reporting of greenhouse gas emissions and removals: it specifies principles and requirements for the design, development, management, reporting and verification of an organization's GHG inventory.

- ISO 14064-2:2006 Greenhouse gases - Part 2: Specification with guidance at the project level for quantification, monitoring and reporting of greenhouse gas emission reductions or removal enhancements: it specifies principles and requirements and provides guidance at the project level for quantification, monitoring and reporting of activities intended to cause GHG emission reductions. It includes requirements for planning a GHG project, for identifying and selecting GHG sources, for monitoring, quantifying, documenting and reporting GHG project performances and for managing data quality.

- ISO 14064-3:2006 Greenhouse gases - Part 3: Specification with guidance for the validation and verification of greenhouse gas assertions specifies requirements for selecting GHG validators/verifiers, establishing the level of assurance, objectives, criteria and scope, determining the validation approach, assessing GHG data, information, information systems and controls, and preparing validation statements. It can be applied to organizational or GHG project quantification, including GHG quantification, monitoring and reporting carried out in accordance with ISO 14064-1 or ISO 14064-2.

- ISO 14040:2006 Environmental management - Life cycle assessment -- Principles and framework describes criteria and framework for life cycle assessment (LCA) and includes the definition of the goal and scope of each LCA phase, as well as the relationship between the LCA phases, reporting, critical review and limitations of the LCA, and conditions for use of value choices. ISO 14040:2006 covers life cycle assessment and life cycle inventory studies, but it does not describe the technique, nor specify methods for each phase. The application of LCA results is considered during the definition of the goal (and the scope), but the application itself is beyond the scope of this International Standard. 
- ISO 14044:2006 Environmental management - Life cycle assessment - Requirements and guidelines specifies requirements and provides guidelines for life cycle assessment in accordance with principles and framework of ISO 14040:2006. It covers life cycle assessment and life cycle inventory studies.

According to voluntary or regulatory drivers, an airport operator can decide to measure and manage its GHG emissions. More detail for US airports is provided in the ACRP Report 11 (Kim et al., 2009). It has yet to be told that a GHG management programme at airports could be established within a formalized structure for identifying an environmental issue and regulatory requirements, formulating and implementing a plan to address and mitigate the issue, to monitor progress, and to review periodically the scheme and its results.

\section{Considerations on the development of airport GHG emission inventories.}

The availability of sufficiently detailed estimates of emissions on the territory is required to evaluate the environmental impact effects of new or existing emission sources (as may be an airport) and to develop procedures for reducing emissions. An inventory of emissions serves as a tool to better understand the sources of emissions and then to provide a quantitative estimate of the pressure emissive on a certain territory. In general, an inventory of emissions lists and quantifies air pollutants emitted to or removed from the atmosphere in amounts per some unit time by type of (airport and non-airport) sources. Collecting information on emissions for monitoring trends and assessing future scenarios, benchmarking emissions against thresholds, creating input data for dispersion models to determine pollution concentrations and establishing mitigation programs are some of the specific objectives of the emissions inventory. It is clear that the owners of the sources must first be identified, as well as pollutant sources and the pollutants they produce; the limits of inventories must subsequently be demarcated, and after choosing the most appropriate method, emissions must be calculated. The inventory can also provide information on the activities that cause emissions and background on the methods used to make the calculations.

Emission inventories are usually distinguished according to different parameters: spatial scale (from sub municipal to national), type of emission sources (point, linear, areal) and emissive activities considered, species of pollutants treated, methodological approach (top down and bottom up). With regard to the activities responsible for the production of emissions, the nomenclature used in Europe to encode their variety and number is given by EMEP-CORINAIR (2006). Activities are thus classified into 11 macro sectors, 56 sectors and 260 activities. Within this classification, activities that are responsible for airport emissions are divided as follows: i. domestic airport traffic (landing and take-off (LTO) cycles $<1000 \mathrm{~m}$ ); ii. international airport traffic (LTO cycles $<1000 \mathrm{~m})$; iii. national cruise traffic $(>1000 \mathrm{~m})$; iv. international cruise traffic $(>1000 \mathrm{~m})$; v. ground access vehicles.

Contrary to a general inventory of emissions related with air quality objectives and local effects of pollutants, a greenhouse gas inventory does not set objectives purely local, but it directs efforts towards the quantification of the liability of an area compared to a global problem as climate change, also in view of possible improvements. A greenhouse gas inventory can be thus the reference for the evaluation of pre-and post-operam actions aimed at reducing the greenhouse effect, as well as for their monitoring over time. Policy makers, in fact, should use greenhouse gas inventories to track emission trends, to develop strategies or policies and to assess progress.

The principles by which the inventory of GHG emissions has to be prepared can reflect several factors: the inventory has to include the appropriate facilities and types of emissions sources to meet goals established by entities that intend to register emission reductions; it must also be drawn using well documented quantification methods and emissions factors, as well as managing data quality. The inventory then has to be prepared in a transparent way to re-tabulate, if needed, the emissions already presented.

An airport inventory of GHG emissions, indeed, can allow to identify the sources and annual quantity of emissions, as well as the ownership for avoiding double counting when aggregate inventories are conducted at a regional or industry level. In this view an inventory of greenhouse gases can become the benchmark against which to measure the achievement of quantitative targets set at the political level in the fight against climate change.

From the perspective of an airport operator, there are so many reasons why he might decide to measure and to manage its GHG emissions. In general, the results of an inventory represent information needed to identify which sources have to be controlled to reduce the formation of certain pollutants. Airport sources of GHG emissions include aviation emissions, airport operator emissions and other airport-related emissions. Airport sources of GHG emissions are defined in Table 1.

According to Ranganathan et al. (2004), as referred by ACI Guidance Manual (2009) and by ACRP-R-11 (Kim 
et al., 2009), there are three "scope" categories of emissions sources: i. GHG emissions from sources owned or controlled by the airport operator (scope 1); ii. GHG emissions from the off-site generation of electricity purchased by the airport operator (scope 2); iii. GHG emissions from airport-related activities from sources not owned or controlled by the airport operator (scope 3). Each scope category identifies the ownership and control of emissions sources, as well as expertise for handling the emissions.

According to Kim et al. (2009b), the emission corresponding to each source by type of emission process are shown in Table 2. Table 3, in turn, shows the categorization of the airport and airport-related sources in each scope category and by type of ownership or control. Emissions from APU, GSE, GAV, and airport infrastructure are considered the main sources of GHGs. Aircrafts are probably the most cited air pollutant source; as is noted in FAA studies reported in technical literature since 2005, they can produce the same types of emissions as cars. Aircraft jet engines, like many other vehicle engines, produce carbon dioxide $\left(\mathrm{CO}_{2}\right)$, water vapor $\left(\mathrm{H}_{2} \mathrm{O}\right)$, nitrogen oxides $\left(\mathrm{NO}_{\mathrm{x}}\right)$, carbon monoxide $(\mathrm{CO})$, oxides of sulfur $\left(\mathrm{SO}_{\mathrm{x}}\right)$, unburned or partially combusted hydrocarbons (also known as volatile organic compounds), particulates, and other trace compounds.

Airports can play a role in reducing their impact on climate change by addressing emissions in ground transportation, energy use in buildings, and associated indirect emissions. All greenhouse gas inventories measure carbon dioxide emissions, but beyond carbon dioxide different inventories can include different greenhouse gasses. The most significant GHG associated with an airport operations is carbon dioxide $\left(\mathrm{CO}_{2}\right)$ and a greenhouse gases emissions inventory often focus only on $\mathrm{CO}_{2}$; if an inventory includes other GHGs, they are reported as "carbon dioxide equivalent" or $\mathrm{CO}_{2}$-eq (Kim et al., 2009a).

Based on guidance provided by Ranganathan et al. (2004), as well as experience gained by airport operators from developing GHG inventories, the availability of data and resources will need to be assessed to determine the pollutants to be accounted for in the inventory. There are three recommended levels of pollutant categories that can be used as a guide: i. inventory that only considers $\mathrm{CO}_{2}$ (level 1); ii. inventory that considers six Kyoto pollutants (level 2); iii. inventory that considers all pollutants including the six Kyoto pollutants, precursors and any others exerting a GHG effect (level 3). A level 2 inventory is the recommended level for an airport inventory.

For the global nature of the GHGs effect, emissions from sources outside the confines of the airport must be considered. GAV emissions have to be attributed to the airport which they refer. Emissions during the cruise phase and during the LTO cycle (landing and take-off cycle) must be allocated to the departure airport. The procedure can be complicated by the presence of a multi-leg flights; in order to avoids double counting, aircraft emissions should not be allocated to the departure and final destination of multi-leg flights but rather to individual legs of a flight (Kim et al., 2009a). It could argue that, in fact, the nature and scope of the airport operator's actions can be driven by the motivation for addressing GHG emissions. Moreover, different airports have different reasons or drivers for addressing GHG emissions. Under the Kyoto Protocol, emissions associated with airports including domestic aviation and ground transportation are included within national inventories and targets. In Europe, airports with large emissions sources, such as their own power stations, have been included in the emissions trading scheme (ETS) since 2009. In some other countries airports are required by local regulation to conduct inventories and report emissions. Many airports conduct GHG emissions inventories on an entirely voluntary basis, possibly motivated by corporate social responsibility, sustainability policy or community interests. Thus, the inventories that have been prepared to date, many of which employ methodologies specifically related to local needs and circumstances, represent an initial start at identifying emissions at airports.

Recognizing some deficiencies in developing inventories, the Transportation Research Board's Airport Cooperative Research Program embarked on the preparation of a guidebook concerning the preparation of airport greenhouse gas emission inventories (Kim et al., 2009). Suggesting the methodological path to follow in accounting for GHG emissions, the overall inventory development procedure suggested by the ACRP-R 11 guide (Kim et al., 2009) represents currently the main reference to remedy the piecemeal and disconnected realization of emission inventories.

\section{Methods of calculating emissions}

\subsection{Methods for calculating emissions by source}

The assessment of air pollution associated with the operations of airport infrastructure can be done through the estimation of emissions from various activities at the airport and, then, through the preparation of an inventory of emissions.

GHG emissions are generally calculated using a combination of emission factors and activity data, i.e. emissions are calculated by multiplying activity data with an emission factor. In general, the method used in an inventory 
to estimate emissions is as follows:

$$
E_{i}=A \times F E_{i}
$$

where:

$$
\begin{aligned}
E_{i}= & \text { the emission of pollutant } i \\
A= & \text { an appropriate indicator of activity related to the amount emitted } \\
F E_{i}= & \text { emission factor for pollutant } i \text { and the activity expressed by } A \text {, i.e. the mass of pollutant emitted } \\
& \text { by a unit quantity of the indicator }
\end{aligned}
$$

The international literature suggests inventory methodologies, methods for air quality assessments, and reliable methodologies for the estimation of emissions induced by aircraft near the ground (Wilcox, 1992; Webb et al., 1997; USEPA, 2011). In order to obtain this estimate, a good indicator of the individual aircraft is the Landing and Take Off cycle (LTO), which includes all activities and operations of an aircraft near the airport below the altitude of $1000 \mathrm{~m}$ (i.e. the standard height into the mixing zone, about equal to $3000 \mathrm{ft}$ ). The most common approach to calculate GHG emissions is performed through the application of specific emission factors (expressed in terms of mass of pollutant emitted per unit of fuel), relating to the condition of maximum thrust of the engine derived from experimental measurements at the test-bed for different models of engines. The IPCC has developed and revised over time guidelines for greenhouse gas inventories referring to a hierarchy of calculation approaches ranging from the application of generic emission factors to direct monitoring.

The standard LTO cycle begins when the aircraft crosses the mixing zone and it approaches to the airport on its descent path from cruising altitude, lands, and taxis to the gate. The cycle continues as the aircraft taxis to the desired runway for takeoff and climb out, and it ends as the aircraft reaches the cruising altitude. The standard LTO cycle consists of landing approach, taxi/idle-in, taxi/idle-out, take-off and climb out. Most aircraft go through this sequence during a complete standard operating cycle. Emissions during the cruise phase and during the LTO cycle (landing and take-off cycle) must be attributed to the departure airport; the procedure is complicated by the presence of a flight that runs multiple stopovers (Kim et al., 2009a). Prefixed powers provided by the engine and the fuel consumption characteristics for each type of engine correspond to each phase of the standard cycle. In addition, for each phase, the emission factors are expressed as a percentage of the emission corresponding to that of the maximum thrust and the estimate of emission is obtained by the product between the emission factor and the fuel consumption. The results of the single assessment are the emissions of different pollutants for each phase of the landing-takeoff cycle performed by each engine on the vehicles (Rosa et al., 2007).

The afore mentioned guidebook on preparing airport greenhouse gas emissions inventories, elaborated by Airport Cooperative Research Program in 2009, specifies how to calculate emissions from each airport source (aircraft and APU, ground support equipment, ground access vehicle, stationary source, waste management activity) and how to apply carbon dioxide $\left(\mathrm{CO}_{2}\right)$ equivalencies (Kim et al., 2009a, Chapter 3); the methods overviewed by the above mentioned guidebook correspond to the six Kyoto pollutants (or pollutant categorized as level 2), focusing on $\mathrm{CO}_{2}, \mathrm{CH}_{4}, \mathrm{~N}_{2} \mathrm{O}$. The same guidebook summarizes methods for each source and suggests the database (IPCC, EIA, USEPA, etc.) from which to acquire emission factors, as well as procedures through which possibly derive the most appropriate emission factors according to the needs of the specific inventory.

Table 4 reports a brief description of the proposed methods for the calculation of emissions by each source. We would like to stress the descriptive intent of what is reported here and that the above mentioned guidebook is certainly a comprehensive guide on the subject. The same ACRP guidebook on preparing airport GHG emissions inventories reports detailed examples for emissions calculations and application of $\mathrm{CO}_{2}$ equivalencies by source.

\subsection{Methods for calculating $\mathrm{CO}_{2}$ equivalencies}

The use of equivalence methods arises from the need to compare each different pollutant from its actual influence on climate. The $\mathrm{CO}_{2}$ equivalencies need to be developed after the identification of each applicable source and the calculation of emissions from each pollutant. Understanding the impact of $\mathrm{CO}_{2}$ on the climate and the subsequent evolution in time is fundamental to understand the hypotheses assumptions underlying the various methods of equivalence.

A brief description of the effects on climate change produced by the GHG gases has been anticipated in the introduction section; now it simply wishes to emphasize the contribution of GHGs to the greenhouse effect, which can be computed by considering both the radiative forcing of the gas and its atmospheric concentration, as well as the persistence of the gases in the atmosphere. 
In the same section, in addition, the Global Warming Potential (GWP) concept was introduced and defined; it represents the combined effect of persistence time in the atmosphere for each gas and of its specific efficacy in the absorption of infrared radiation emitted by the Earth. The GPW is therefore a measure of how a given greenhouse gases contribute to global warming than $\mathrm{CO}_{2}$. GWP, calculated over a specific time interval (commonly 100 years), is expressed by the ratio of the warming of atmosphere caused by one GHG to that caused by a similar mass of carbon dioxide, i.e. GWP represents a factor of carbon dioxide whose GWP is standardized to 1 .

In order to calculate the GWP of a gas under consideration, changes in radiative forcing (RF) as a function of time have to be considered. The expression reported in the literature for the calculation of the GWP for the component $i$ with the global mean radiative forcing $\left(\mathrm{RF}_{\mathrm{i}}\right)$, is the following:

$$
G W P_{i}=\frac{\int_{0}^{T H} R F_{i}(t) d t}{\int_{0}^{T H} R F_{\mathrm{CO}_{2}}(t) d t}
$$

The integration, performed over the chosen time horizon $\mathrm{TH}$, represents the ratio between the area under the radiative forcing curve for a unit emission of one type of gas and the area under the radiative forcing curve for $\mathrm{CO}_{2}$. In order to obtain $\mathrm{CO}_{2}$-equivalent $\left(\mathrm{CO}_{2 \mathrm{e}}\right)$, the mass emissions of a non- $\mathrm{CO}_{2}$ agent has to be multiplied by its GWP. ICCP recommends a time horizon of 100 years for the purpose of the GHG emissions inventory. Table 5 shows GWP value established by IPCC (2007). Lots of comments on the positive and negative features of GWPs are indeed reported by Appendix D to ACRP Report 11 (Kim et al., 2009b), to which reference is made. For the development of an inventory of GHG emissions, the mass emissions of individual non- $\mathrm{CO}_{2}$ pollutants and its $\mathrm{CO}_{2 \mathrm{e}}$ emissions have to be collected. The calculation of $\mathrm{CO}_{2}$ equivalencies for non- $\mathrm{CO}_{2}$ pollutants requires that information is known about the mass emissions of each non- $\mathrm{CO}_{2}$ pollutant, as well as the appropriate GWP. The 100-year time horizon of the non- $\mathrm{CO}_{2}$ pollutants refers to the corresponding time horizon for the GWP values. If for example it wants to calculate $\mathrm{CO}_{2 \mathrm{e}}$ emissions for 15 metric tons of $\mathrm{CH}_{4}$, the corresponding $\mathrm{GWP}_{100}$ value is equal to 25 (see Table 5); it follows that the corresponding $\mathrm{CO}_{2 \mathrm{e}}$ emission is equal to 375 metric tons.

As an alternative to the Global Potential Warming (GPW), The Global Temperature Potential (GTP) metric can be used for evaluations of greenhouse gas and other effects on climatic change. Differently from the GPW, the GTP can be useful to focus on a particular target at a set date because it does not emphasize the integrated effects over time, but what the effects would be at the end of a given time horizon. Shine et al., (2005) define the Global Temperature Potential as the ratio between the global mean temperature change at a chosen time (the end of a time horizon, $\mathrm{TH}$ ) due to an emission (pulse or sustained) of a gas $i$ to a reference gas (e.g., $\mathrm{CO}_{2}$ ):

$$
G T P_{i}^{T H}=\frac{\Delta T_{i}^{T H}}{\Delta T_{C O_{2}}^{T H}}
$$

The GTP indicates global mean temperature change as a result of emissions of a greenhouse gas; it requires knowledge of the same parameters as the GWP metric (radiative efficiency and lifetimes), as well as information on the thermal sensitivity of the various parts of climatic system for different time periods from external actions. In addition, the response times for the climate system must be known, particularly if the lifetime of a gas is very different from the lifetime of the reference gas. The inclusion of the response times for the climate system makes the GTP values lower than the corresponding GWP values for pulse emissions of gases with shorter lifetimes than the reference gas. In any case, several authors agree that GWP remains the recommended metric to compare future climate impacts of emissions of long-lived climate gases (Forster et al., 2007).

\section{New references to the environmental sustainability at airports}

\subsection{Calculating the carbon footprint}

The practice of calculating the carbon footprint has been widespread since some years in airport contexts as a tool to monitor performances in relation to emissions of greenhouse gases and to identify areas where new interventions are needed to improve environmental performance, i.e. to enhance the choices already made or planned by the airport operator. Activities to be carried out for quantifying the carbon footprint were set at an international level from 1988 by the Greenhouse Gas Protocol; more specifically, the Corporate Accounting and Reporting Standard (Corporate Standard), which set out the guidelines for quantifying and reporting GHG emissions, and the Project Accounting Protocol and Guidelines, useful for quantifying GHG reductions from mitigation projects, were developed (Ranganathan et al., 2004). 
In order to determine the carbon footprint in the airport context a gradual process must be followed (Iride, 2009). First, the operating limits of the airport system to be measured have to be established and these must be understood in terms of definition of the airport grounds and of identification of operators responsible for emissions (i.e. due to their activities carried out at the airport or correlated to it). Only then it can proceed with the definition of the emission inventory. This involves not only the reporting of $\mathrm{CO}_{2}$ emissions, but also the reporting of emissions of GHG gases (or at least the main), which are then expressed in terms of $\mathrm{CO}_{2}$-equivalent $\left(\mathrm{CO}_{2 \mathrm{e}}\right)$. At this point, inventory items can be aggregated by scope (scope 1,2,3), or for chapters already outlined by the manager (transport, energy use, buildings, food and drink, waste); it can be assigned to these items what the airport operator accounted for management purposes. This will make it possible to obtain an output value of $\mathrm{CO}_{2}$-equivalent $\left(\mathrm{CO}_{2 \mathrm{e}}\right)$ by emission source or by scope (e.g. categories of sources by scope), on which to base subsequent choices of optimization. Finally, the drafting of the Carbon Footprint report can be carried out in accordance with the conditions defined in the GHG Protocol. Airports also need to have certified carbon footprint in accordance with UNI-ISO 14064; for such certifications, independently verified, evidence must be provided to the Airport Carbon Accreditation Administrator. It should be noted here that Airport Carbon Accreditation is a certification programme, launched by da ACI Europe by June 2009, representing the European carbon standard for airports; it has been developed, indeed, to assess and recognize efforts of airport operators to manage and reduce their greenhouse gas emissions, just trying to encourage airport operators to take steps to reduce $\mathrm{CO}_{2}$ emissions. Finally, to become Airport Carbon Accredited, an airport must fulfill (step by step) the following criteria: i. mapping, which leads to the calculation of carbon footprint and the preparation of the corresponding report ii. reduction, which requires the fulfillment of all requirements of mapping and the demonstration of the effectiveness of actions to reduce emissions, iii. optimization, which involves commitments with third parties that operate within the airport (handlers, catering companies, other job categories that are available) and with local authorities and organizations that manage surface transport, iv. neutrality, which is achieved by neutralizing the remaining amount of direct emissions, through compensating actions.

Since 2009 the Airport Carbon Accreditation program has achieved an overall reduction of 749 thousand tons of $\mathrm{CO}_{2}$ emissions. To emphasize the importance of the afore mentioned program is provided below some information given by the annual report section of the Airport Carbon Accreditation for the year 2010-2011. The above report says that the 17 European airports participating in the program in 2009/2010 became 43 the following year; albeit at different levels, all are accredited (Airport Carbon Accreditation, Annual Report, 2010-2011). Airport Carbon Accreditation requires that airports report on $\mathrm{CO}_{2}$ emissions only, but under the programme, airports may report voluntarily on other greenhouse gases. By way of example, Table 6 reports the aggregated emissions starting from all participants data relative to the last two years. Each airport operator has to set a goal of achieving Carbon Neutral status; in order to fulfill this focus, activities that generate carbon dioxide (and other GHG) emissions should be reduced or eliminated. Examples of measures are outlined in the following section.

\subsection{Greenhouse Gas mitigation options and measures to reduce emissions}

The adoption of measures to prevent, minimize or mitigate the adverse effects of aviation-related air pollution and the adverse impact of aviation on climate change, as outlined in ACI's Policy and Recommended Practices Handbook (Oh, 2008), is the main target of airport stakeholders; today more than ever they are called upon to assess the local air quality at and around the airport. Assessment should be based on air quality regulation or standards to determine if the current or planned airport activities are expected to comply with the applicable regulations for each pollutant species. There are three main types of actions: i. measurements of the concentrations of specific pollutant species of concern; ii. development of inventories of emission sources to quantify the airport and airport-related sources for each pollutant species; iii. estimates of the expected pollutant concentrations at receptor locations by dispersion modeling.

Mitigation of local air quality pollution is best achieved by reducing emissions at source. To reduce emissions, ACI Guidance Manual (2009) recommends measures that: i. regulate the amount of emissions by setting emissions standards on sources or prescribing restrictions on operations (regulatory measures); ii. reduce emissions through the implementation of technical solutions (technical measures); iii. influence the emission levels through reducing fuel consumption or changing operating times of emissions sources or procedures (operational measures); iv. create economic incentives to change activities or equipment with lower emissions (economic or market-based measures), including local emission charges and global or regional emission trading schemes. These can be also implemented as a combination of several categories of measures.

Table 7 summarizes possible actions and options should be implemented by airport operators to reduce the main polluting emissions. For emissions reduction opportunities, or where reductions in the adverse impact of aviation 
on climate change can be achieved, it is therefore important to distinguish between aircraft emissions and those emissions directly associated with airports. Moreover, particularly in the development of greenhouse gas emissions inventories, responsibility or ownership and location (on and off airport) have to be clearly demarked. Then, as mentioned in the previous section, basing on a complete inventory, an airport has to develop goals and action plans to achieve the ultimate target of being carbon neutral.

\section{Conclusions}

In the context of climate change issues and related enforcement actions undertaken at various levels, the GHG emissions inventory is a data collection process that could be useful for understanding aviation (past and present) effects on environment. For airport infrastructures, the determination of the greenhouse gases emitted presents normally great complexity, since these structures are highly articulated systems where several operators co-exist and pursue many different activities. In addition, one of the reasons in support of tools such as inventories of GHG emissions in the airport, lies in the awareness that environmental investments can mitigate the risk of incurring to much higher adjustment costs that in later times may be necessary.

With a descriptive and informative intent, this paper without claiming to be exhaustive provides an overview of the main issues of air pollution associated with airport operations. The article frames the airport sources and components contributing to greenhouse gas emissions and in particular focuses on reasons for developing greenhouse gas emission inventories and on the usefulness of these inventories. After an brief description of the most recent international and national standard and recommendations on this topic, the article traces the essential elements in the methodology to be followed for preparing an airport-specific inventory of greenhouse gas emissions; for this purpose the specialized literature on the subject (to which for further study the reader is referred) was collected and examined in depth. Methods for calculating emissions are also summarized and reviewed. Finally, the new references to the environmental sustainability at airports, as well as the main measures to be taken to reduce emissions are also identified and commented on. It emerges clearly that the needs to control and reporting of greenhouse gases are correlated to the enhancement of the design choices made and to the orientation of development strategies; moreover, the optimization and the energy efficiency must be also considered as a tool of economic management.

The idea of this article stems from the fact that the quantification of greenhouse gas emissions through a GHG emissions inventory that each airport operator should carry out, not only on a voluntary basis, consistent with the regulatory framework, is also the key tool to enable further opportunities of development and improvement. These activities have to follow the quantification of GHG gas emissions, but the full knowledge of the environment "performances" of the airport is essential to gain access to later stages, and in some cases also to funding opportunities, and to implement the actions necessary to achieve the environmental sustainability goals.

\section{References}

Airport Carbon Accreditation (2011), Annual Report, 2010-2011, Airport's Council International Europe. [Online] Available: http://www.airportcarbonaccreditation.org (June 2011)

Berry, F., Gillhespy, S. \& Rogers, J. (2008). Airport Sustainability Practices. A Synthesis of Airport Practice. ACRP Synthesis Report 10. (1st ed.).Washington, DC: Transportation Research Board

EMEP/CORINAIR Emission Inventory Guidebook (2006). Copenhagen, Denmark: European Environmental Agency (EEA). [Online] Available: http://www.eea.europa.eu/publications/EMEPCORINAIR4 (December 2006)

Forster, P., V. Ramaswamy, P. Artaxo, T. Berntsen, R. Betts, D.W. Fahey, J. Haywood, J. Lean, D.C. Lowe, G. Myhre, J. Nganga, R. Prinn, G. Raga, M. Schulz \& R. Van Dorland, (2007). Changes in Atmospheric Constituents and in Radiative Forcing. In: Climate Change 2007: The Physical Science Basis. Contribution of Working Group I to the Fourth Assessment Report of the Intergovernmental Panel on Climate Change. Cambridge, UK and NY (US): Cambridge University Press, (Chapter 2).

Guidance Manual: Airport Greenhouse Gas Emissions Management (2009). ACI World Environment Standing Committee (1st Edition), November 2009. [Online] Available: http://www.zurich-airport.com/Portaldata/2/Resources/documents_unternehmen/umwelt_und_laerm/ACI_Greeh ouse_Gas_Manual_2009.pdf

Herzog, T. (2009). World Greenhouse Gas Emissions in 2005. WRI Working Paper. World Resources Institute. [Online] Available: http://www.wri.org/publication/navigating-the-numbers.

Inventory of US Greenhouse Gas Emissions and Sinks: 1990-2009 (2011), US Greenhouse Gas Inventory Report and annexes, [Online] Available:http://epa.gov/climatechange/emissions/usinventoryreport.html (April 2011). 
Iride (2009). Carbon Footprint at airports. Newsletter 5(11), pp 1-4. Roma (Italy): Institute for Engineering and the research of Sustainability.

Kim, B., Bassarab, R. Vigilante, M., \& Waitz, I. A. (2009a). Guidebook on Preparing Airport Greenhouse Gas Emissions Inventories. ACRP Report 11, pp 1-64. Washington, DC: Transportation Research Board. [Online] Available: http://onlinepubs.trb.org/onlinepubs/acrp/acrp_rpt_011.pdf

Kim, B., Bassarab, R. Vigilante, M., \& Waitz, I. A. (2009b). Appendices to ACRP Report 11: Guidebook on Preparing Airport GHG Emissions Inventories, [Online] Available: http://www.trb.org/Publications/Blurbs/Appendices_to_ACRP_Report_11_Guidebook_on_Preparin_160740.asp $\mathrm{x}$ (December 2009).

Lepore Andrea (2009). Attacco al clima: dal cielo e dal mare! (Attack on climate: from the sky and the sea!). Roma (Italy): Greenpeace Italy. [Online] Available:www.greenpeace.it

Oh Xavier (2008). ACI Policy and Recommended Practices Handbook. (6th ed.). Geneva, Switzerland: Airports Council International. [Online] Available: http://www.airports.org/aci

Pachauri, R.K. \& Reisinger, A. (2007). Climate Change 2007: Synthesis Report. Contribution of Working Groups I, II and III to the Fourth Assessment Report of the Intergovernmental Panel on Climate Change. Geneva, Switzerland, pp. 1-104. [Online] Available: http://www.ipcc.ch/publications _ipcc_fourth_assessment_report_synthesis_report.htm

Ranganathan, J., Corbier, L., Bhatia, P., Schmitz, S., Gage P., \& Oren, K. (2004). The Greenhouse Gas Protocol, A Corporate Accounting and Reporting Standard. (Revised Edition). Washington, DC: World Resource Institute, World Business Council for Sustainable Development. [Online] Available: http://www.ghgprotocol.org/files/ghgp/public/ghg-protocol-revised.pdf (April 2004.)

Rosa M., Pistollato S. \& Zemello C. (2007). La stima delle emissioni aeroportuali [The estimate of airport emissions]. Regione Veneto, Italy: ARPAV, February, 2007.

Sausen R., Isaksen, I., Grewe, V., Hauglustaine D., Lee D. S., Gunnar, M., Köhler, M. O., Pitari, G., Schuman, U., Frode Stordal, F. \& Zerefos, C. (2005). Aviation radiative forcing in 2000: An update on IPCC (1999). Meteorologische Zeitschrift, 14(4), 555-561, August 2005, DOI: 10.1127/0941-2948/2005/0049.

Scaturro, F. \& Siciliano, G. (2009). Analisi delle implicazioni dell'applicazione dell'Emission Trading Scheme al trasporto aereo [Analysis of the implications of emissions trading scheme to aviation]. [Online] Available: http://www.sietitalia.org/wpsiet/Scaturro-Siciliano_SIET.pdf (June 2009).

Shine K.P, Fuglestvedt J.S, Hailemariam K, \&N. Stuber (2005). Alternatives to the global warming potential for comparing climate impacts of emissions of greenhouse gases. Climate Change, 688(3), 281-302, DOI: 10.1007/s10584-005-1146-9.

Stewart, B., Klin, T., \& Vigilante, M. (2011). Climate Change Adaptation and Preparedness Planning for Airports. Adapting Transportation to the Impacts of Climate Change, State of the Practice 2011. Transportation Research Circular E-C152, pp. 37-44. Washington DC (USA): Transportation Research Board. [Online] Available: http://onlinepubs.trb.org...nepubs/circulars/ec152.pdf (June 2011).

Van Begin, G. \& Van Staden M. (2010). Harmonisation in inventories. City typology as the basis for policy. 2010 KPMG Advisory N.V. in the Netherlands, [Online] Available: www.kpmg.com

Webb, D., Pernigotti, A., \& Liang, P. (1997). Air Quality Procedures for Civilian Airports and Air Force Bases, Air Quality Handbook and Handbook Methodologies. Washington DC (USA): United States Department of Transportation, Federal Aviation Administration.

Wilcox, R. (1992). Procedure for Emission Inventory Preparation, Vol. IV: Mobile Sources: Emission from Aircraft. United States Environmental Protection Agency. [Online] Available: http://www.epa.gov/oms/invntory/r92009.pdf (chapter 5) 
Table 1. Airport sources of GHG emissions

\begin{tabular}{|c|c|}
\hline Source category & Specific source \\
\hline $\begin{array}{l}\text { Aircraft emissions } \\
\text { (jet, turboprop, } \\
\text { piston) }\end{array}$ & $\begin{array}{l}\text { Aircraft engine emissions for holding before approach above 3,000 ft, approach and landing, take-off } \\
\text { and initial climb (ground to 3,000 ft), taxiing and queuing (ground). }\end{array}$ \\
\hline $\begin{array}{l}\text { Auxiliary Power } \\
\text { Units (APU) }\end{array}$ & The on-board engine supporting the aircraft while parks on the ground. \\
\hline $\begin{array}{c}\text { Ground access } \\
\text { vehicles (GAV) }\end{array}$ & $\begin{array}{l}\text { All on-road or highway vehicle trips generated by the users of the airport. GAV include all vehicles } \\
\text { traveling to and from, as well as within the airport public roadway system (excluding GSE). On-road } \\
\text { and highway vehicles include: vehicles transporting passengers and vehicles using airport parking, } \\
\text { vehicles transporting airport and tenant employees, including vehicles in employee parking lots, } \\
\text { vehicles transporting cargo, airport-owned vehicles. }\end{array}$ \\
\hline $\begin{array}{c}\text { Stationary } \\
\text { Sources/Facility } \\
\text { Power } \\
\end{array}$ & $\begin{array}{l}\text { Power/electricity consumption, airport facility boilers, heaters, and generators, aircraft engine testing, } \\
\text { maintenance activities (surface coating/painting, degreasing), fuels used by food concessions, etc. }\end{array}$ \\
\hline $\begin{array}{l}\text { Ground support } \\
\text { equipment (GSE) }\end{array}$ & $\begin{array}{l}\text { A variety of ground equipment services for commercial aircraft used to unload and to load passengers } \\
\text { and to freight at an airport. GSE consist of vehicles that do not leave the airfield: aircraft tugs, air start } \\
\text { units, loaders, tractors, air-conditioning units, ground power units, cargo-moving equipment, service } \\
\text { vehicles, etc. Off-road vehicles and vehicles of the airport operator that maintain airport facilities are } \\
\text { also included. According to ACRP-R } 11 \text { (2009) emissions can be reported in aggregate, but data } \\
\text { collection requires knowledge of different types of GSE used by airport operators. }\end{array}$ \\
\hline $\begin{array}{c}\text { Airport } \\
\text { construction } \\
\text { activities }\end{array}$ & $\begin{array}{l}\text { Vehicles consuming fuels during the construction process: runway extension or development, terminal } \\
\text { building and gate area expansion, new taxiways, etc. }\end{array}$ \\
\hline Training fires & $\begin{array}{l}\text { Fuel usage for planned training activities. Emissions are mostly due to combustion from the burning of } \\
\text { the fuel, as well as emissions associated from the use of fire extinguishers or other equipment. }\end{array}$ \\
\hline $\begin{array}{l}\text { Waste management } \\
\text { activities }\end{array}$ & $\begin{array}{l}\text { Activities reflect any processes or use of equipment specifically geared toward waste management: } \\
\text { sorting of waste, shipping to waste management facilities, recycling, and incineration. }\end{array}$ \\
\hline Other & All other sources such as local airport companies with industrial processes, farming activities, etc. \\
\hline
\end{tabular}

Table 2. Emissions corresponding to each source by type of emission process (Kim et al., 2009b).

\begin{tabular}{|c|c|c|c|c|c|c|c|c|c|c|c|c|}
\hline \multirow[b]{2}{*}{ source } & \multicolumn{6}{|c|}{ primary } & \multicolumn{6}{|c|}{ precursors and others } \\
\hline & $\mathrm{CO}_{2}$ & $\mathrm{CH}_{4}$ & $\mathrm{~N}_{2} \mathrm{O}$ & $\mathrm{SF}_{6}$ & $\mathrm{HFC}$ & $\mathrm{PFC}$ & $\mathrm{H}_{2} \mathrm{O}$ & PM & Sox & Nox & $\mathrm{CO}$ & NMVOC \\
\hline \multicolumn{13}{|l|}{ aircraft } \\
\hline \multicolumn{13}{|l|}{ APU } \\
\hline GAV & & & & & & & & & & & & $*$ \\
\hline Stationary source & & & & & & & & & & & & $*$ \\
\hline GSE & & & & & & & & & & & & $*$ \\
\hline Construction & & & & & & & & & & & & $*$ \\
\hline Waste Management & & & & & & & & & & & & $*$ \\
\hline Training Fires & & & & & & & & & & & & \\
\hline
\end{tabular}

(*) and other halogenated gases emission process: combustion non-combustion 
Table 3. Airport and airport-related sources by scope category and type of ownership or control

\begin{tabular}{|c|c|c|c|c|c|c|}
\hline \multirow{2}{*}{ source } & \multicolumn{3}{|c|}{ scope } & \multicolumn{3}{|c|}{ ownership and control } \\
\hline & 1 & 2 & 3 & Airport & Tenant & Public \\
\hline Heat, cooling, electricity production (electric power plant) & & & & $\bullet$ & & \\
\hline Aircraft owned by the airport operator & & & & $\bullet$ & & \\
\hline $\begin{array}{l}\text { Vehicles for passenger transport and maintenance, machinery } \\
\text { operating both airside and landside }\end{array}$ & & & & $\bullet$ & & \\
\hline $\begin{array}{l}\text { Airport maintenance activities: cleaning, repairs, green spaces, } \\
\text { farming, etc. }\end{array}$ & & & & $\bullet$ & & \\
\hline $\begin{array}{l}\text { Ground Support Equipment: equipment for handling and servicing } \\
\text { aircrafts on the ground. }\end{array}$ & & & & $\bullet$ & & \\
\hline Diesel generators for emergency power & & & & $\bullet$ & & \\
\hline Stationary Sources (electricity consumed in Scope 2) & & & & $\bullet$ & & \\
\hline Fire training & & & & $\bullet$ & & \\
\hline Waste disposed on-site: incineration or treatment & & & & $\bullet$ & & \\
\hline Off-site electricity (and heating or cooling) generation. & & & & $\bullet$ & & \\
\hline Aircraft main engines during taxiing and queuing ${ }^{(*)}$ & & & (a) & & $\bullet$ & \\
\hline Aircraft Auxiliary Power Units (APU) & & & (a) & & $\bullet$ & \\
\hline $\begin{array}{l}\text { Aircraft main engines in the LTO cycle, excluding taxiing. Aircraft } \\
\text { emissions during cruise on flights to or from airport }\end{array}$ & & & (b) & & $\bullet$ & \\
\hline $\begin{array}{l}\text { Landside Road traffic/Ground Access Vehicles (GAV) vehicles } \\
\text { operating on airport property }\end{array}$ & & & (a) & & $\bullet$ & \\
\hline $\begin{array}{l}\text { Landside Road traffic/Ground Access Vehicles (GAV): vehicles } \\
\text { operating off-site: private cars, hotel and car rental shuttles, buses, } \\
\text { goods delivery trucks, freight trucks. }\end{array}$ & & & (b) & & • & $\bullet$ \\
\hline $\begin{array}{l}\text { Ground Support Equipment (GSE) for the handling and servicing of } \\
\text { aircraft on the ground, if airport could provide alternative fuels or } \\
\text { otherwise influence operation; otherwise scope (3b) }\end{array}$ & & & (a) & & $\bullet$ & \\
\hline Construction activities & & & (a) & $\bullet$ & $\bullet$ & \\
\hline Electricity (and heating or cooling) generation other external energy & & & (b) & & $\bullet$ & \\
\hline $\begin{array}{l}\text { Aircraft and engine maintenance activities and infrastructure for } \\
\text { aircraft maintenance }\end{array}$ & & & (b) & & $\bullet$ & \\
\hline Rail traffic and other ground transport related to the airport & & & (b) & & & $\bullet$ \\
\hline Off-site waste incineration or recycling from airport sources & & & (b) & & $\bullet$ & \\
\hline Other Stationary Sources & & & & & $\bullet$ & \\
\hline Other & & & & $\bullet$ & $\bullet$ & \\
\hline
\end{tabular}

Note that the above definitions of Scope 1, 2, 3 a and $3 b$ are consistent with Ranganathan et al.,(2004), Kim et al. (2009) and ACI Manual (2009).

${ }^{(*)}$ Landing emissions could be Scope $3^{(\text {a) }}$

${ }^{\text {(a) }}$ Scope 3 sources an airport operator can influence; ${ }^{(b)}$ Scope 3 sources an airport operator cannot influence 
Table 4. Methods proposed by Kim et al. (2009) for the calculation of emissions by source.

\begin{tabular}{|c|c|}
\hline Source & Method \\
\hline : & $\begin{array}{l}\text { Method } 1 \text { requires fuel sales data and appropriate emission factors to calculate the total emissions for departure } \\
\text { flights; it can also account for emissions due to the use APU, because this is powered by the aircraft. } \\
\text { Method } 2 \text { requires data on the sale of fuel in combination with models to calculate separately the LTO cycle } \\
\text { emissions. The method allows to separate the emissions that occur at the airport (LTO cycle) from those that occur } \\
\text { outside of the airport (during cruise). } \\
\text { Method } 3 \text { is based on models to calculate the fuel consumption and emissions associated with all phases of flight } \\
\text { (including cruise). The main model used is AEDT/SAGE, which requires detailed information on aircraft fleet, } \\
\text { flight schedules, aircraft performance and trajectory. }\end{array}$ \\
\hline 芴 & $\begin{array}{l}\text { Method } 1 \text { requires fuel sales data of Ground Support Equipment and appropriate emission factors to calculate the } \\
\text { emissions. } \\
\text { Method } 2 \text { is based on the models to calculate emissions; emission factors for representative equipment can be } \\
\text { determined applying models as USEPA's NONROAD2005 (or similar models for US airports such as CARB's } \\
\text { OFFROAD2007). Data input required by models are: annual hours of use, category of equipment, engine } \\
\text { characteristics, date manufactured, horsepower of the equipment. }\end{array}$ \\
\hline 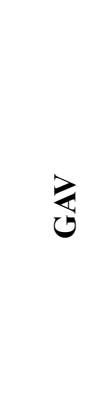 & $\begin{array}{l}\text { Method } 1 \text { requires to collect average vehicle miles traveled (VMT) data for all vehicles, including the total } \\
\text { origin-destination distance (to allow proper accounting of GHG emissions based on the influence of the airport) } \\
\text { and the categorization of each vehicle by fuel type. Total VMT and vehicle fuel economy data are necessary to } \\
\text { calculate GAV fuel consumption that multiplied by appropriate emission factors gives emission estimates. } \\
\text { Method } 2 \text { is similar to Method } 1 \text {. The main difference consist in use vehicle-specific VMT data (e.g., cars, trucks, } \\
\text { motorcycles, etc.) and other specific categorizations (e.g., vehicle age, mileage, emissions controls, etc.) with } \\
\text { appropriate vehicle-specific emission factors. } \\
\text { Method } 3 \text { uses vehicle-specific VMT data to generate } \mathrm{CO}_{2} \text { emission factors for different vehicle types through } \\
\text { MOBILE } 6.2 \text { and other models as necessary. }\end{array}$ \\
\hline 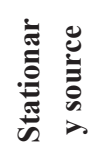 & $\begin{array}{l}\text { Methods for calculating these emissions can be divided into two groups: electricity usage and combustion } \\
\text { activities from stationary sources. Combustion activities from stationary sources can be accounted for by two } \\
\text { alternative methods: method 1: use of average emission factors, method } 2 \text { : use of specific emission factors. }\end{array}$ \\
\hline 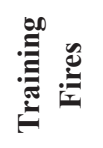 & $\begin{array}{l}\text { Methods for calculating GHG emissions by this source use appropriate emission factors associated with the fuel } \\
\text { data used in training fire. Emissions from the use of fire extinguishers should also be accounted for. }\end{array}$ \\
\hline 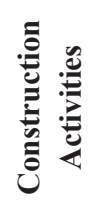 & $\begin{array}{l}\text { GHG emissions calculations for construction activities require emission factors generated using models (e.g. } \\
\text { NONROAD2005 or other models) or obtained from the manufacturers. } \\
\text { Information on construction equipment activity also needs to be estimated. }\end{array}$ \\
\hline
\end{tabular}


Table 5. GWP value established by IPCC (2007)

\begin{tabular}{|l|l|l|l|l|l|}
\hline \multirow{2}{*}{ GHG } & \multirow{2}{*}{ lifetime (years) } & \multirow{2}{*}{$\begin{array}{c}\text { Radiative } \\
\text { forcing } \\
{\left[\mathrm{m}^{-2} \mathrm{ppb}^{-1}\right]}\end{array}$} & \multicolumn{2}{c|}{ Global Warming Potential for time horizon } \\
\cline { 5 - 6 } & & $1.40 \times 10^{-5}$ & 1 & 100 years & 500 years \\
\hline $\mathrm{CO}_{2}$ & 200 & $3.70 \times 10^{-4}$ & 72 & 1 & 1 \\
\hline $\mathrm{CH}_{4}$ & 12 & $3.03 \times 10^{-5}$ & 289 & 29 & 7.6 \\
\hline $\mathrm{N}_{2} \mathrm{O}$ & 114 & 0.52 & 16.300 & 22.800 & 32.600 \\
\hline $\mathrm{SF} 6$ & 3.200 & 0.19 & 12.000 & 14.800 & 12.200 \\
\hline $\mathrm{HFC}$ & 270 & 0.10 & 5.210 & 7.390 & 11.200 \\
\hline PFC-14 & 50.000 & & & & \\
\hline
\end{tabular}

Table 6. $\mathrm{CO}_{2}$ aggregated emissions relative to the last biennium (Airport Carbon Accreditation, 2011)

\begin{tabular}{|c|c|c|c|c|}
\hline \multirow[b]{2}{*}{ Variable } & \multicolumn{2}{|c|}{ Year 1} & \multicolumn{2}{|c|}{ Year 2} \\
\hline & Emissions & $\begin{array}{l}\text { Number of } \\
\text { Airports }\end{array}$ & Emissions & $\begin{array}{l}\text { Number of } \\
\text { Airports }\end{array}$ \\
\hline $\begin{array}{l}\text { Aggregate carbon footprint for the first } 12 \text { months (from the date } \\
\text { of application) for emissions under airports' direct control }\end{array}$ & $803,05 \mathrm{tCO}_{2}$ & \multirow[t]{2}{*}{17} & $\begin{array}{c}2,275,469 \\
\mathrm{tCO}_{2}\end{array}$ & \multirow[t]{2}{*}{43} \\
\hline Carbon footprint per passenger & $2.6 \mathrm{~kg} \mathrm{CO}_{2}$ & & $3.73 \mathrm{~kg} \mathrm{CO}_{2}$ & \\
\hline $\begin{array}{l}\text { Reduction in emissions from sources under airports' direct } \\
\text { control (Level } 2 \text { and above) }\end{array}$ & $51,657 \mathrm{t} \mathrm{CO}_{2}$ & \multirow[t]{2}{*}{9} & $51,819 \mathrm{tCO}_{2}$ & \multirow[t]{2}{*}{19} \\
\hline Carbon footprint reduction per passenger & $0.351 \mathrm{~kg} \mathrm{CO} 2$ & & $0.11 \mathrm{~kg} \mathrm{CO}$ & \\
\hline $\begin{array}{l}\text { Total carbon footprint for the first } 12 \text { months (from the date of } \\
\text { application) for emissions sources which an airport may guide or } \\
\text { influence (level } 3 \text { and above) }\end{array}$ & $2,397,62 \mathrm{tCO}_{2}$ & \multirow[t]{2}{*}{6} & $\begin{array}{c}6,643,266 \\
\mathrm{tCO}_{2}\end{array}$ & \multirow[t]{2}{*}{13} \\
\hline $\begin{array}{l}\text { Reductions from emissions sources which an airport may guide } \\
\text { or influence }\end{array}$ & $359,73 \mathrm{tCO}_{2}$ & & $675,12 \mathrm{tCO}_{2}$ & \\
\hline Total emissions offset (Level 3+) & $13,13 \mathrm{tCO}_{2}$ & 4 & $85,602 \mathrm{tCO}_{2}$ & 8 \\
\hline
\end{tabular}

Table 7. Actions to reduce polluting emissions

\section{Configuration of the airport layout and actions on GSE and GAV}

- Optimization of runway layouts

- Infrastructure design of new terminal buildings, as well as retrofits projects for existing terminal buildings should employ GHG technology

- Provision of pre-conditioned air and electricity to gates

- Using GSE, ground vehicles (airside/ landside) and land transport with low fuel consumptions and emissions

- Using GAV with low fuel consumptions and emissions and efficient planning of routes

Improving the environmental performance of aircrafts and reducing aircraft empty weight

- Reductions in aircraft taxiing, queuing and APU usage

- Ongoing maintenance of the cell to maintain the high aerodynamic

- Ongoing maintenance of the engine and other mechanical parts

- Mass reduction and proper positioning of the centre of gravity

\section{Land use planning and management techniques of the flight}

- Choice of routes

- Using management techniques of the flight to increase the "fuel-efficiency"

- Reduction of non-commercial flights (e.g. training flights) and restricting operations 